\title{
Géolinguistique
}

19 | 2019

Varia

\section{A presença dos Açores em duas comunidades de Florianópolis (SC): aspetos prosódico-entoacionais}

La présence des Açores dans deux communautés de Florianópolis (SC) : aspects prosodico-intonatifs

The Presence of the Azores in Two Communities of Florianópolis (SC): ProsodicIntonational Aspects

Lurdes de Castro Moutinho e Izabel Christine Seara

\section{(2) OpenEdition}

\section{Journals}

Edição electrónica

URL: http://journals.openedition.org/geolinguistique/1633

ISSN: 2650-8176

\section{Editora}

UGA Éditions/Université Grenoble Alpes

\section{Edição impressa}

ISBN: 978-2-37747-166-9

ISSN: 0761-9081

\section{Refêrencia eletrónica}

Lurdes de Castro Moutinho et Izabel Christine Seara, «A presença dos Açores em duas comunidades de Florianópolis (SC): aspetos prosódico-entoacionais », Géolinguistique [En ligne], 19 | 2019, mis en ligne le 09 décembre 2019, consulté le 19 décembre 2019. URL : http://journals.openedition.org/ geolinguistique/1633

Este documento foi criado de forma automática no dia 19 dezembro 2019.

Géolinguistique 


\title{
A presença dos Açores em duas comunidades de Florianópolis (SC): aspetos prosódico-entoacionais
}

\author{
La présence des Açores dans deux communautés de Florianópolis (SC) : aspects \\ prosodico-intonatifs \\ The Presence of the Azores in Two Communities of Florianópolis (SC): Prosodic- \\ Intonational Aspects
}

Lurdes de Castro Moutinho e Izabel Christine Seara

\section{Primeiras considerações}

1 Neste artigo pretendemos abordar aspetos prosódico-entoacionais, referentes à duração e curva de $F_{0}$ de frases declarativas neutras e interrogativas totais, produzidas por portugueses e brasileiros. $O$ estudo será realizado com base nos dados de:

- duas comunidades do interior de Florianópolis - capital de Santa Catarina (Santo Antônio de Lisboa e Ribeirão da Ilha);

- duas freguesias açorianas: Vila Nova, na ilha Terceira; Fenais da Ajuda - na ilha de São Miguel. Para controle, usaremos ainda dados de um informante da cidade de Aveiro, localizada em Portugal continental (ver localização dos lugares referidos nas figs. 2 e 3).

2 A comparação dos dados de análise obtidos, para estas variedades linguísticas, deve permitir-nos observar as caraterísticas de cada uma destas comunidades e aferir da presença/ausência de traços prosódico-entoacionais que sejam indiciadores da presença da colonização açoriana na fala florianopolitana.

Este estudo, desenvolvido no âmbito do Projeto AMPER-POR, motivado por outros estudos anteriores (Seara \& Moutinho, 2019; Moutinho et al., 2015, Moutinho \& Coimbra, 2010; Bernardes, 2008, entre outros), pretende contribuir para um conhecimento mais aprofundado da variação prosódico-entoacional dos falares catarinenses, mais especificamente do falar da capital do estado de Santa Catarina 
(região não-urbana), bem como dos falares insulares portugueses. Nesse sentido, procuramos caraterizar as modalidades declarativa neutra e interrogativa total dessa variedade dialectal, a partir de dados de duas comunidades no interior da capital catarinense, acima referidas e compará-las, seguidamente, com dados linguísticos também já apurados para as freguesias açorianas supra-citadas. Esta nossa motivação advém do facto de estes povoados catarinenses serem referidos como sendo alguns dos povoados colonizados por açorianos (ver fig. 1).

Figura 1. - Mapa de Santa Catarina mostrando, em azul claro, as regiões de colonização açoriana.

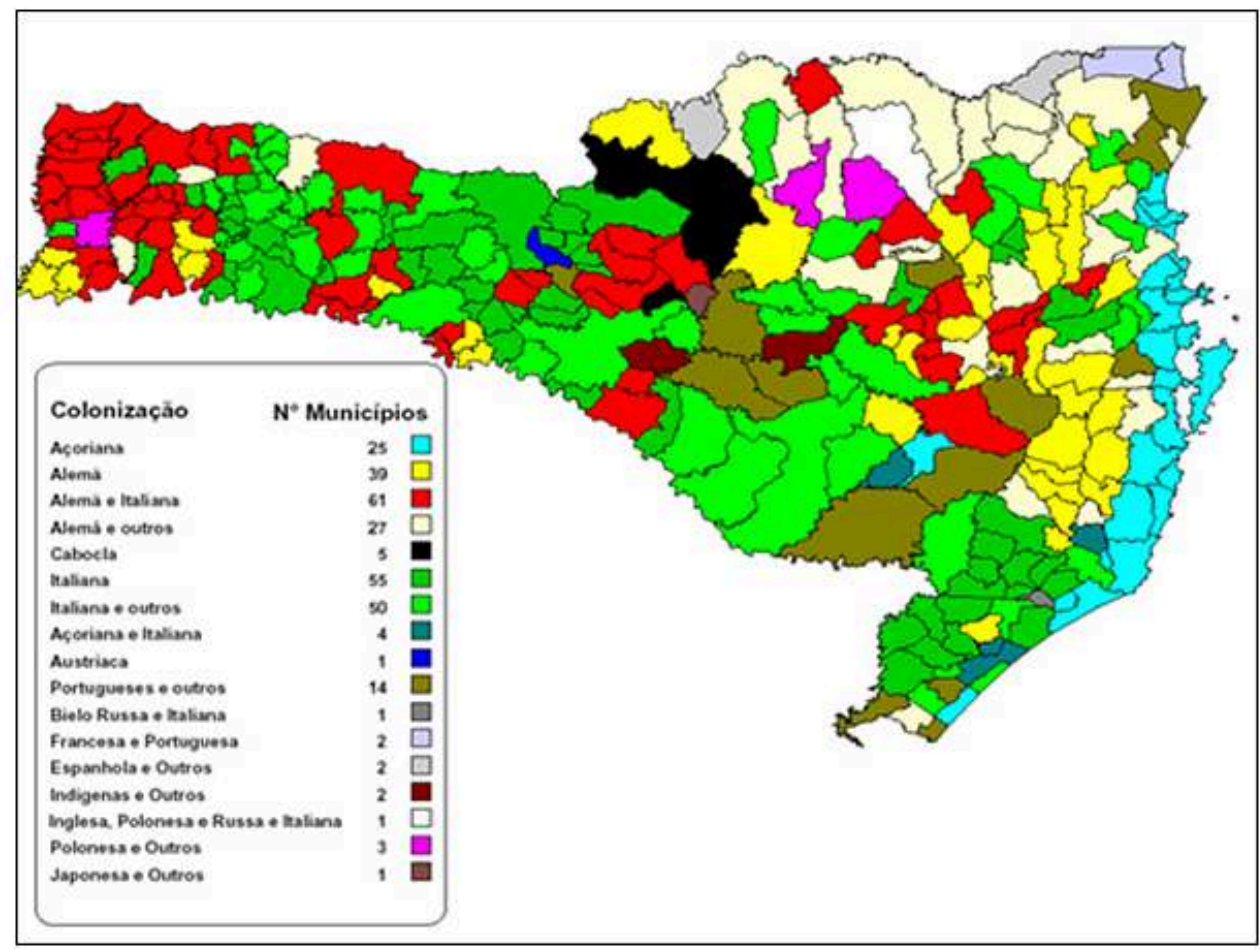

Fonte: <https://desconstitucionalizados.wordpress.com/2011/09/04/429/>.

4 Segundo Piazza 1983, conforme citado por Furlan, 1989, «os povoadores açorianos se fixaram em todo o litoral catarinense, desde São Francisco até ao sul de Laguna» (apud Furlan, 1989: 152). O mapa mostrado na figura 1 exibe (em azul claro) a região colonizada por açorianos.

5 Furlan crescenta ainda que, no século XIX, na ilha de Santa Catarina (hoje Florianópolis), em consequência do crescimento demográfico das populações lusoaçorianas, foram criadas as freguesias de Nossa Senhora da Lapa do Ribeira (hoje Ribeirão da Ilha), Santo Antônio (hoje Santo Antônio de Lisboa), Nossa Senhora da Conceição da Lagoa (hoje Lagoa da Conceição) e ainda Rio Tavares. Este último, citado por Cabral (1970), é um povoado também fundado, ou com população reforçada, por açorianos. Nos apontamentos de Piazza (1983 apud Furlan, 1989) estão referenciadas então as duas comunidades que serão aqui estudadas (Ribeirão da Ilha e Santo Antônio de Lisboa).

6 Encarnação (2008) sugere que os primeiros açorianos chegaram à ilha de Florianópolis por volta de 1689 , no entanto, a colonização só teve início efetivo no século XVIII. Inicialmente eram vilarejos de pescadores que ainda hoje preservam as tradições e 
costumes trazidos pelos açorianos. E, segundo a autora, isso se deve a um certo isolamento da ilha nos últimos tempos. Essas tradições podem ser vistas nas festas religiosas, danças folclóricas, como o boi-de-mamão e, também, no vocabulário e no modo de falar dos habitantes.

Observe, na figura 2, a posição geográfica de Florianópolis no Brasil e a localização do Ribeirão da Ilha e de Santo Antônio de Lisboa na parte insular de Florianópolis (Sul e Norte, respetivamente).

Figura 2. - (a) Mapa do Brasil com a localização do Estado de Santa Catarina e de Florianópolis (capital do estado); (b) parte insular de Florianópolis, com setas apontando para Santo Antônio de Lisboa, localizado ao Norte da ilha (em lilás), e Ribeirão da Ilha, localizado ao Sul da ilha (em ocre).

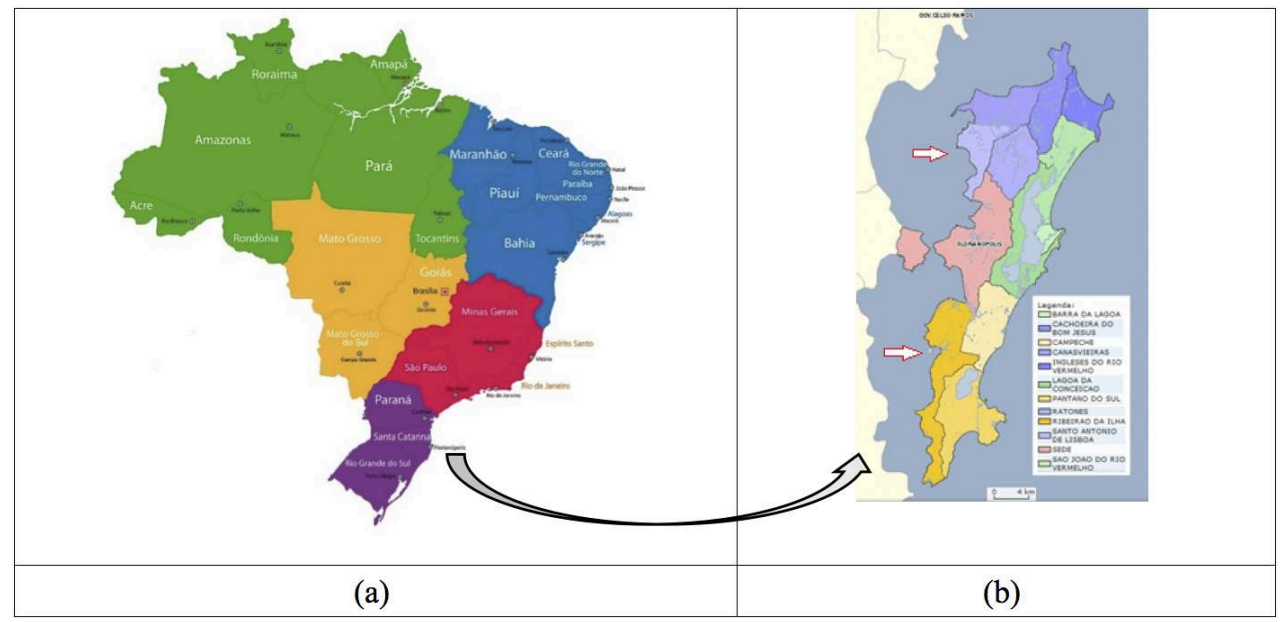

Fonte (a): <www.estudopratico.com.br/wp-content/[...]/estados-brasil.jpg>

Fonte (b): <http://www.mobfloripa.com.br/[...]Mapa distritos administrativos.jpg>.

8 Inúmeros estudos têm analisado dados de diferentes cidades catarinenses que não foram colonizadas por catarinenses, como, por exemplo, Nunes \& Seara (2019), Nunes et al. (2015) e Uliano et al. (2015). No entanto, atualmente, as pesquisas têm focalizado principalmente o falar da capital de Santa Catarina (Florianópolis) que, designadamente, apresenta características bastante peculiares, como, por exemplo, os estudos de Seara et al. (2018) e Seara \& Sosa (2017), entre outros. Todavia, resultados de estudos linguísticos relativos aos habitantes das comunidades do interior da capital (região não-urbana) são bastante raros (por exemplo, Seara, 2019; Brescancini, 2015; Silva, 2008; Encarnação, 2008) e, em geral, não se referem a aspetos prosódicoentoacionais. Atualmente, já se percebem diferenças entre o falar dessas localidades não-urbanas e o da região urbana de Florianópolis. Inclusive, pesquisas realizadas recentemente têm evidenciado uma mudança a nível da entoação em falantes mais jovens dessas comunidades (Seara \& Sosa, 2017; Seara et al., 2018).

9 Assim, foram gravados e analisados dados de informantes nativos (um homem e uma mulher) das comunidades de Santo Antônio de Lisboa e Ribeirão da Ilha. Foram selecionados para o presente estudo os dados dos falantes masculinos dessas duas comunidades. Para efeito de comparação com o PE, contaremos com o mesmo tipo de dados dos Açores referentes a duas localidades das ilhas de São Miguel (Fenais da Ajuda) e Terceira (Vila Nova), de onde seriam oriundos os açorianos que colonizaram as localidades brasileiras, aqui estudadas. Como já dissemos, contaremos ainda com os dados de locutores de Aveiro, Portugal continental. Nas comunidades portuguesas, 
analisaremos também apenas as produções dos informantes masculinos. Observe, na figura 3, as localidades portuguesas aqui estudadas.

Figura 3. - Mapa de: (a) Portugal continental com a indicação (na seta) da cidade de Aveiro; (b) as nove ilhas dos Açores (parte insular de Portugal) com as ilhas Terceira e São Miguel circuladas em vermelho.

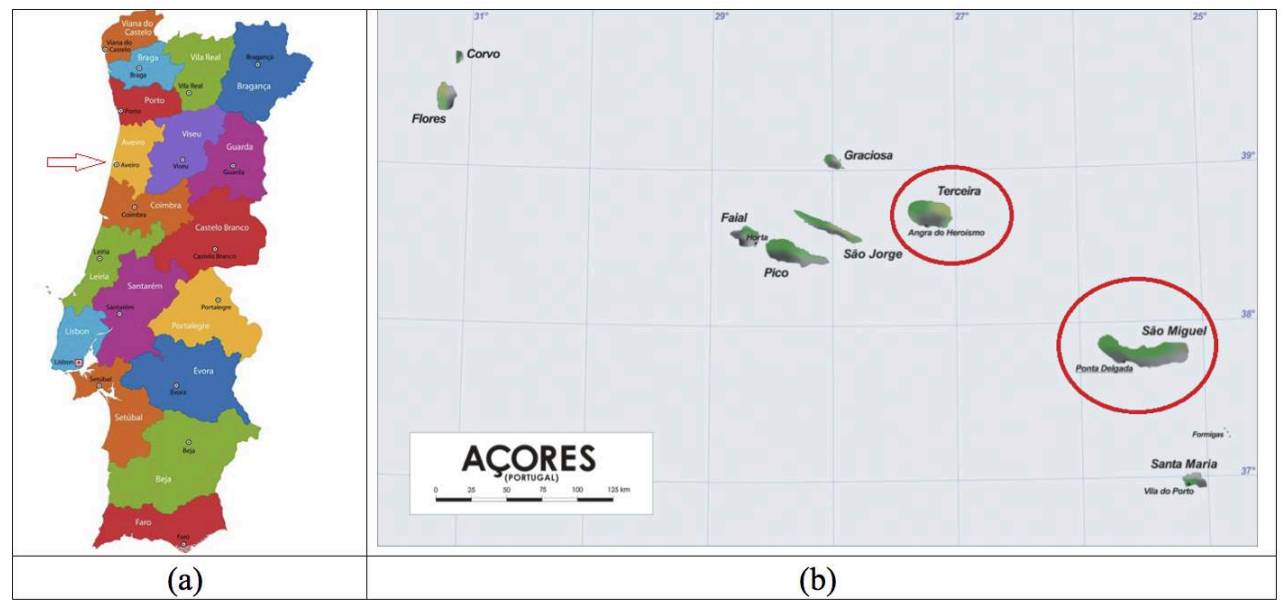

Fonte (a): <https://i.pinimg.com/[...]/e67b4e824af3d2cb4cf40a2889e93ae8.jpg>

Fonte (b): <https://byacores.com/wp-content/[...]/mapa-acores-1024x625.png>

10 Na figura 3, são mostrados os mapas de Portugal Continental com a indicação da localização da cidade de Aveiro e também de Portugal Insular, indicando a localização das ilhas de São Miguel e Terceira.

11 Neste estudo, faremos então a descrição da implementação fonética das curvas entoacionais de frases declarativas neutras e interrogativas totais, produzidas por falantes das comunidades brasileiras e portuguesas aqui estudadas, para a perceção da existência ou não da presença açoriana no falar florianopolitano não-urbano.

\section{As questões de pesquisa}

Considerando-se que Florianópolis (conhecida como ilha de Santa Catarina, uma vez que é composta por uma parte situada no continente do Brasil e outra em uma ilha) foi colonizada por açorianos e que as comunidades localizadas no interior da ilha apresentam uma variedade conhecida como o manezinho, que mantém muitas das características do português europeu, procuramos responder às seguintes questões de pesquisa:

1. Serão verificadas, nas caraterísticas prosódico-entoacionais de frases declarativas e interrogativas produzidas por falantes de duas comunidades do interior da ilha de Santa Catarina, marcas dialectais que remetam para as características prosódico-entoacionais de falantes das ilhas dos Açores?

2. Verificadas semelhanças, elas estarão relacionadas com os movimentos da curva de $F_{0}$, localização e alinhamento do pico de $F_{0}$ nas sílabas? Ou estarão relacionadas com variações de valores de $F_{0}$ e de duração apresentadas para as frases declarativas neutras e interrogativas totais?

As respostas a essas duas questões evidenciarão a presença ou não dos Açores na ilha de Santa Catarina. 


\subsection{Procedimentos metodológicos}

13 A metodologia empregada neste estudo é baseada nos procedimentos metodológicos utilizados pelo Projeto AMPER-POR. Um dos problemas de investigação sobre a entoação refere-se às metodologias de recolha de dados. Em geral, a comparação entre diferentes estudos é dificultada pelas variadas estratégias metodológicas empregadas na recolha e análise dos dados. No entanto, o Projeto AMPER-POR utiliza uma metodologia de análise de dados que possibilita a comparação entre diferentes falares e modalidades de frase. É esse um dos maiores objetivos do Projeto.

O Projeto AMPER-POR, iniciado no final dos anos 90 para a variedade do português europeu, passa a contar com investigadores para a variedade do português brasileiro desde 2008. Sua metodologia compreende um corpus composto de frases constituídas por imagens. $O$ uso de imagens tem por objetivo evitar a leitura das frases, ou seja, a fala lida. Para a transcrição e etiquetagem das frases gravadas, é usado o programa MatLab ou Praat PRAAT (Boersma \& Weenink, 2018) com aplicações, scripts, especificamente desenvolvidas para o Projeto que são fornecidas a todos os pesquisadores AMPER, sendo, assim, possível a obtenção de dados comparáveis entre todas as línguas românicas estudadas. Os primeiros scripts foram criados, em 1999, por Antonio Romano para Matlab (Universidade de Turim); os desenvolvidos, posteriormente, para o Praat são da responsabilidade de Albert Rilliard (LIMSI, Paris, 2008). Os resultados são obtidos automaticamente, com base na etiquetagem estabelecida, a partir de scripts elaborados para esse fim.

15 A maior parte dos trabalhos na área tem-se baseado em fala lida em laboratório, o que evidentemente introduz um elemento artificial em todos os resultados obtidos. Daí a proposta do projeto AMPER de fazer as coletas de corpora in loco e de usar imagens, para produção das frases pretendidas, possibilitando uma maior naturalidade, mesmo não se tratando de fala espontânea. As imagens, então, propiciam a produção de frases declarativas neutras e interrogativas totais, fornecendo um conjunto de 66 frases com estruturas sintáticas fixas e cobrindo os três tipos de acento lexical que podem ocorrer em português (oxítono, paroxítono e proparoxítono).

16 As frases são produzidas a partir de imagens que são apresentadas aleatoriamente para os sujeitos. Para cada frase, são analisadas três repetições. O banco de dados de cada comunidade pesquisada é composto de três repetições de 66 frases (33 declarativas neutras e 33 interrogativas totais), perfazendo um total de 198 frases para cada informante ( 66 frases $\mathrm{x} 3$ repetições). As frases variam de tamanho, podendo ter de $10 \mathrm{a}$ 14 vogais. Todavia, no presente estudo, estamos considerando apenas as frases com 10 vogais. Assim, considerando-se o número de comunidades estudadas, de informantes, de frases compostas de 10 vogais e de repetições, tem-se um total de 270 enunciados para análise ( 5 comunidades $\mathrm{x} 1$ informante por comunidade $\mathrm{x} 18$ frases (9 declarativas e 9 interrogativas) $\times 3$ repetições).

17 No Quadro 1, são apresentadas as frases de 10 vogais produzidas para as variedades brasileiras e portuguesas. Essas frases são compostas basicamente por sujeito + verbo + objeto. 
Quadro 1. - Frases do corpus AMPER-POR constituídas de 10 sílabas e seus respectivos códigos.

\begin{tabular}{|l|c|c|c|c|}
\hline Decl. & Inter. & Variedades brasileiras & Variedades portuguesas & Cariedades portuguesas \\
\hline kwka/ & kwki & O bisavô gosta do bisavô./? & O capataz toca no capataz./? & O capataz gosta do capataz./? \\
\hline kwpa & kwpi & O bisavô gosta do pássaro./? & O capataz toca no pássaro./? & O capataz gosta da música./? \\
\hline kwta & kwti & O bisavô gosta do Renato./? & O capataz toca no Toneca./? & O capataz gosta do fadista./? \\
\hline pwka & pwki & O pássaro gosta do bisavô./? & O pássaro toca no capataz./? & A música fala do capataz./? \\
\hline pwpa & pwpi & O pássaro gosta do pássaro./? & O pássaro toca no pássaro./? & A música fala da música./? \\
\hline pwta & pwti & O pássaro gosta do Renato./? & O pássaro toca no Toneca./? & A música fala do fadista./? \\
\hline twka & twki & O Renato gosta do bisavô./? & O Toneca toca no capataz./? & O fadista gosta do capataz./? \\
\hline twpa & twpi & o Renato gosta do pássaro./? & O Toneca toca no pássaro./? & O fadista gosta da música./? \\
\hline twta & twti & o Renato gosta do Renato./? & O Toneca toca no Toneca./? & O fadista gosta do fadista./? \\
\hline
\end{tabular}

Depois de feitas as gravações, as frases obtidas são segmentadas e gravadas em arquivos isolados e etiquetadas com os códigos apresentados no Quadro 1. A segmentação das frases e a etiquetagem são realizadas com o auxílio do software Praat (Boersma \& Weenink, 2018) ou Matlab, como já referido. Com as frases segmentadas e etiquetadas, um script gera automaticamente todos os dados numéricos relacionados com a frequência fundamental $\left(F_{0}\right)$, duração e intensidade de cada uma das vogais etiquetadas. Com esses resultados, são gerados gráficos como os apresentados na figura 4 , que resumem e sobrepõem os dados médios de $F_{0}$, duração e intensidade das três repetições.

Figura 4. - Gráfico referente à $F_{0}$, duração e intensidade das vogais presentes na frase: 0 pássaro gosta do Renato.

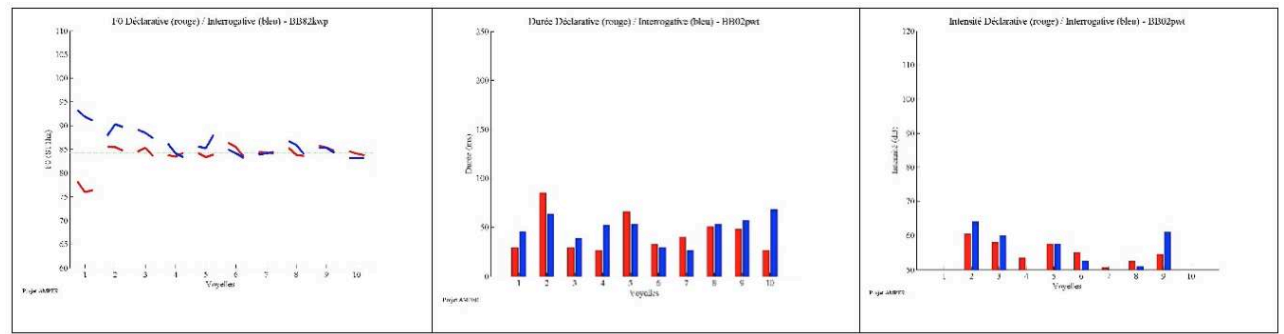

Em vermelho, a frase declarativa e em azul a interrogativa.

19 Com esses dados, analisamos as curvas de $F_{0}$, assim como comparamos os valores de $F_{0}$ (normalizadas em semitons (st)) entre modalidades e entre os informantes. Esses valores serão analisados e comparados tanto no pré-núcleo entoacional (região inicial das frases), quanto no núcleo entoacional (região final das frases). Foram consideradas as posições do pico de $F_{0}$ em cada região, assim como o seu alinhamento (à direita, à 
esquerda ou medial). Foram observadas ainda as diferenças de $F_{0}$ (em st) nas regiões iniciais e finais entre declarativas e interrogativas, além da duração.

\section{Nossos resultados}

Iniciamos a apresentação dos nossos resultados pelas informações obtidas a partir das curvas de $F_{0}$. Primeiramente a partir de uma análise mais geral do comportamento dessas curvas e, na sequência, analisaremos apenas a região nuclear das frases, observando a localização do pico de $F_{0}$ e seu alinhamento na sílaba. A visualização dos gráficos das curvas de $F_{0}$, mostradas na figura 5 , foram geradas automaticamente e nos levam a uma primeira constatação sobre o comportamento das curvas de frases declarativas neutras em relação às curvas de interrogativas totais.

Figura 5. - Gráficos das curvas de $F_{0}$ de frases declarativas neutras (em vermelho) e de interrogativas totais (em azul).

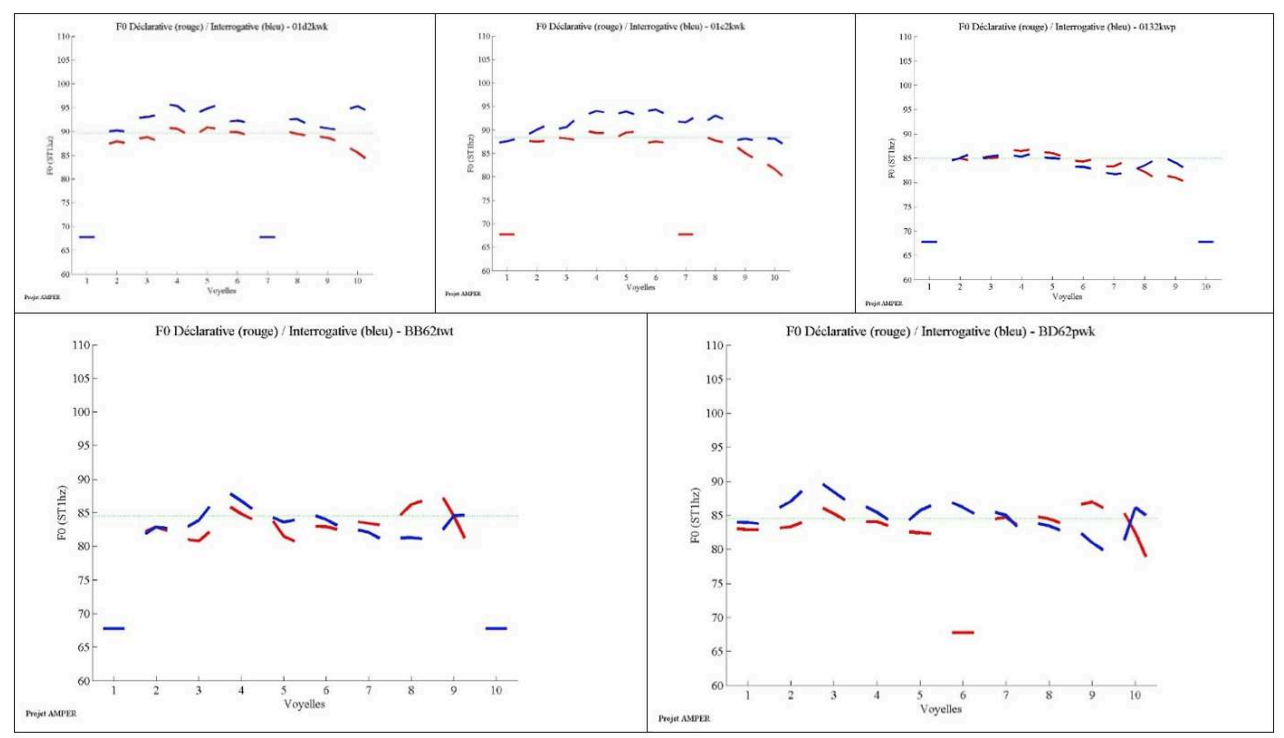

Parte superior do gráfico, lendo da esquerda para a direita: enunciados produzidos por informantes de Vila Nova (01d2), de Fenais da Ajuda (01c2) e de Aveiro (0132). Parte inferior do gráfico, lendo da esquerda para a direita: resultados obtidos para Santo Antônio de Lisboa (BB62) e Ribeirão da Ilha (BD62)

Note que, à exceção de Aveiro, as curvas de $F_{0}$ das frases interrogativas apresentam valores de $F_{0}$ em geral superiores aos valores de $F_{0}$ das frases declarativas. Para os dados das ilhas açorianas, esse comportamento percorre toda a frase do pré-núcleo ao núcleo entoacional. As frases interrogativas apresentam movimento final descendente. Bernardes (2008), pesquisando dados de açorianos ${ }^{1}$, também observou um padrão entoacional de interrogativa com terminal descendente.

Já nos dados relativos à ilha de Florianópolis, esse comportamento de valores de $F_{0}$ superiores para as interrogativas ocorre até antes da região nuclear, onde há uma queda brusca de $F_{0}$ que só volta a subir na sílaba tónica dessa região. Nas curvas de $F_{0}$ produzidas por falantes aveirenses, os valores de $F_{0}$ das interrogativas ou se sobrepõem aos valores de $F_{0}$ das declarativas ou as interrogativas exibem valores mais baixos do 
que a das declarativas, havendo, na região nuclear, uma inversão desse comportamento.

Em resumo, a observação das curvas de $F_{0}$ das frases declarativas e interrogativas mostra que há semelhanças entre as produções dos açorianos e dos florianopolitanos em relação ao $F_{0}$, mais alto nas interrogativas. Entretanto, também mostra diferenças, pois, a curva de $F_{0}$ das interrogativas para os açorianos sempre se apresenta mais alta do que nas declarativas e tem contorno final descendente. No entanto, a curva de $F_{0}$ das interrogativas dos florianopolitanos vai exibir um comportamento inverso na região nuclear, na qual passa a apresentar valores de $F_{0}$ das interrogativas bem mais baixos do que o das declarativas e retrata um contorno final ascendente-descendente ou apenas ascendente. As curvas de $F_{0}$ produzidas por aveirenses vai mostrar um comportamento mais semelhante ao dos florianopolitanos apenas na região nuclear e destoa das produções açorianas tanto na região pré-nuclear, quanto na nuclear. Considerando-se as diferenças de comportamento entre as comunidades verificadas, principalmente, na região nuclear, passamos à observação da sílaba em que se encontra o pico de $F_{0}$ e seu alinhamento na sílaba dessa região entonacional. Observe a Tabela 1.

Tabela 1. - Observações relativas à sílaba em que se encontra o pico de $F_{0}$ e ao alinhamento do pico de $F_{0}$ para a região nuclear concernentes à: localidade de Vila Nova (Terceira) e Fenais da Ajuda (São Miguel) nos Açores, Aveiro em Portugal Continental e Santo Antônio de Lisboa e Ribeirão da llha na parte insular de Florianópolis no Brasil.

\begin{tabular}{|c|c|c|c|c|}
\hline Localidades & \multicolumn{2}{|c|}{ Sílaba em que se encontra o pico de $F_{0}$} & \multicolumn{2}{|c|}{ Alinhamento do pico de $F_{0}$ na sílaba } \\
\hline \multicolumn{5}{|c|}{ Oxítonas } \\
\hline Modalidade & Decl. & Inter. & Decl. & Inter. \\
\hline Vila Nova & pré-tónica2 & tónica & à esquerda & medial \\
\hline Fenais da Ajuda & pré-tónica1 & pré-tónica1 & à esquerda & à esq/medial \\
\hline Aveiro & pré-tónica1 & tónica & à direita & à direita \\
\hline Sto Antônio & pré-tónica2 & tónica & medial & medial \\
\hline Ribeirão & pré-tónica2 & tónica & medial/à esq & medial \\
\hline \multicolumn{5}{|c|}{ Paroxítonas } \\
\hline Vila Nova & pré-tónica1 & tónica & à esquerda & medial \\
\hline Fenais da Ajuda & pré-tónica1 & tónica & à esquerda & medial \\
\hline Aveiro & pré-tónica1 & tónica & à esquerda & à direita \\
\hline Sto Antônio & pré-tón1/tónica & tónica & medial/à esq & à direita \\
\hline Ribeirão & pré-tónica1 & tónica & à esq/medial & à direita \\
\hline \multicolumn{5}{|c|}{ Proparoxítonas } \\
\hline
\end{tabular}




\begin{tabular}{|c|c|c|c|c|}
\hline Vila Nova & tónica & tónica & à esquerda & medial \\
\hline Fenais da Ajuda & tónica & tónica & à esquerda & medial \\
\hline Aveiro & tónica & tónica/pós-tón1 & à esquerda & à direita/à esq. \\
\hline Sto Antônio & tónica & tónica & à esquerda & à direita/medial \\
\hline Ribeirão & tónica & tónica/pós-tón1 & à esq/medial & à dir/à esq \\
\hline
\end{tabular}

Um primeiro apontamento, a partir da Tabela 1, diz respeito às produções açorianas. Como aparentemente a curva de $F_{0}$ das interrogativas totais não apresenta os movimentos na região nuclear que caracterizam essa modalidade apresentando um movimento final descendente, observamos, para essas comunidades, um pequeno movimento circunflexo, característico da interrogativa, que é intra-silábico (alinhamento medial). Isso quer dizer que aparentemente o movimento circunflexo ocorre com frequência na vogal da sílaba tónica, podendo apresentar-se com alinhamento à esquerda na sílaba pré-tónica, apenas no caso das oxítonas.

Já, nas produções de Aveiro, o pico de $F_{0}$, nas interrogativas, ocorre frequentemente nas tónicas e o alinhamento, nesse caso, é sempre à direita. Com respeito às produções brasileiras, o pico de $F_{0}$ das interrogativas localiza-se preferencialmente à direita na tónica, comportamento semelhante ao de Aveiro. Assim, para essas localidades, o movimento do pico de $F_{0}$ que leva a que a perceção da frase interrogativa seja intersilábico, enquanto, nos dados de açorianos, esse movimento parece ser intra-silábico.

Com referência às frases declarativas, os resultados evidenciam um mesmo comportamento para as comunidades em estudo. $O$ pico de $F_{0}$ localiza-se, para a região nuclear formada por vocábulos oxítonos e paroxítonos, na pré-tónica com alinhamento preferencialmente à esquerda, podendo ser também medial. Para a região nuclear composta por vocábulos proparoxítonos, o pico de $F_{0}$ situa-se à esquerda na tónica.

$\mathrm{Na}$ próxima secção, serão analisadas as variações de $F_{0}$ entre as frases declarativas $\mathrm{e}$ interrogativas totais.

\subsection{As variações de valores de $F_{0}$ entre declarativas e interrogativas}

Muitos dos resultados de estudos prosódicos-entoacionais têm sido sustentados em achados resultantes de testes de perceção, como, por exemplo, Milan e Kluge (2017), que estudaram as produções de frases declarativas e interrogativas emitidas por curitibanos. Esse estudo confirmou que diferenças de 3 semitons (st) já são percebidas pelo ouvido humano. Assim as diferenças superiores a 3 st entre os valores de $F_{0}$ de prénúcleos das declarativas neutras e das interrogativas totais indicavam contornos diferentes e foram confirmados, pelas autoras, como significativamente distintos a partir de testes estatísticos. Outros estudos, como 't Hart (1981), Consoni \& Ferreira Netto (2008); Martins \& Ferreira Netto (2010), entre outros, também mostraram, com base em testes estatísticos, que os ouvintes percebem com acuidade variações de 3 st ou mais. 
Com base nesses resultados, foram investigados valores de $F_{0}$ normalizados em semitons com o objetivo de verificar se haveria, na região pré-nuclear entre frases declarativas e interrogativas, diferenças superiores a 3 st que pudessem já no prénúcleo discriminar essas duas modalidades como ocorre nas produções de brasileiros da cidade de Curitiba (capital do estado do Paraná) (Milan, 2015). Os resultados são apresentados na Tabela 2.

Tabela 2. - Variação superior a 3 st nos valores de $\boldsymbol{F}_{0}$ na região pré-nuclear de frases declarativas neutras e interrogativas totais.

\begin{tabular}{|l|c|l|l|}
\hline Variação acima de 3 st & Oxítonas & Paroxítonas & Proparoxítonas \\
\hline Vila Nova & 4,25 st a 5,09 st & & \\
\hline Fenais da Ajuda & 3,24 st a 4,66 st & 3,74 st a 6,67 st & 3,26 st a 4,12 st \\
\hline Aveiro & & 3,21 st & \\
\hline Santo Antônio de Lisboa & 3,08 st a 3,59 st & 3,13 st a 3,65 st & 4,07 st a 6,20 st \\
\hline Ribeirão da Ilha & 3,35 st a 4,38 st & 3,13 st a 7,33 st & 5,54 st a 13,27 st \\
\hline
\end{tabular}

31 A Tabela 2 apresenta a variação de $F_{0}$ superior a 3 st verificada entre frases declarativas e interrogativas a partir da observação de regiões do pré-núcleo entoacional. A análise dos dados evidencia que as maiores diferenças aparecem em produções de Ribeirão da Ilha, variando entre 3,35 e 13,27 st. A faixa de variação das demais comunidades é menos alargada, havendo para Aveiro e Vila Nova poucos casos de variação acima de 3 st. Isso parece indicar que a comunidade para a qual certamente se identificariam declarativas e interrogativas totais a partir da região pré-nuclear seria a comunidade de Ribeirão da Ilha. As análises dos dados indicaram também que nem todas as regiões pré-nucleares apresentam tais diferenças, como ocorre para a comunidade de Aveiro e Vila Nova. Nesses casos, muito provavelmente as frases declarativas e interrogativas não seriam identificadas por suas regiões pré-nucleares. Testes percetuais estão sendo aplicados com o objetivo de verificar se as diferenças apontadas seriam percebidas pelos ouvintes. Resultados desses testes serão tema de outra publicação.

Se observarmos agora a variação encontrada na região nuclear entre frases declarativas e interrogativas, veremos que, para todas as comunidades investigadas, foram verificadas diferenças, conforme Tabela 3. Isso seria de se esperar uma vez que é no núcleo entoacional que categoricamente são discriminadas as frases declarativas das interrogativas.

Tabela 3. - Variação superior a 3 st nos valores de $\boldsymbol{F}_{0}$ na região nuclear de frases declarativas neutras e interrogativas totais.

\begin{tabular}{|l|c|l|l|}
\hline Variação acima de 3 st & Oxítonas & Paroxítonas & Proparoxítonas \\
\hline Vila Nova & 4,45 st a 9,69 st & 3,00 st a 9,60 st & 8,51 st a 9,34 st \\
\hline
\end{tabular}




\begin{tabular}{|l|c|c|c|}
\hline Fenais da Ajuda & 3,14 st a 6,85 st & 3,23 st a 6,63 st & 3,69 st a 8,97 st \\
\hline Aveiro & 4,23 st & 3,67 st a 5,89 st & 3,18 st a 4,98 st \\
\hline Santo Antônio de Lisboa & 3,21 st a 6,91 st & 3,45 st a 5,69 st & 3,74 st a 4,82 st \\
\hline Ribeirão da Ilha & 3,59 st a 6,74 st & 3,90 st a 8,21 st & 3,09 st a 8,55 st \\
\hline
\end{tabular}

$\mathrm{Na}$ Tabela 3, as diferenças observadas são bem mais frequentes, ocorrendo em praticamente todas as vogais produzidas na região nuclear, sendo, na sua maioria, bastante superiores aos 3 st. As diferenças mais evidentes são encontradas nas comunidades de Ribeirão da Ilha e Vila Nova. Novamente, observamos aqui uma semelhança de comportamento entre Ribeirão (comunidade brasileira) e Vila Nova (comunidade açoriana da ilha Terceira).

Passemos à análise da duração das vogais que compõem as frases declarativas e interrogativas nas comunidades aqui investigadas.

\subsection{Duração}

Iniciamos a análise dos dados de duração por uma observação atenta dos histogramas gerados pelos scripts do MatLab, como os exemplos mostrados na figura 6 .

Figura 6. - Histogramas dos valores médios de duração $(\mathrm{ms})$ das vogais de frases declarativas (em vermelho) e interrogativas (em azul).

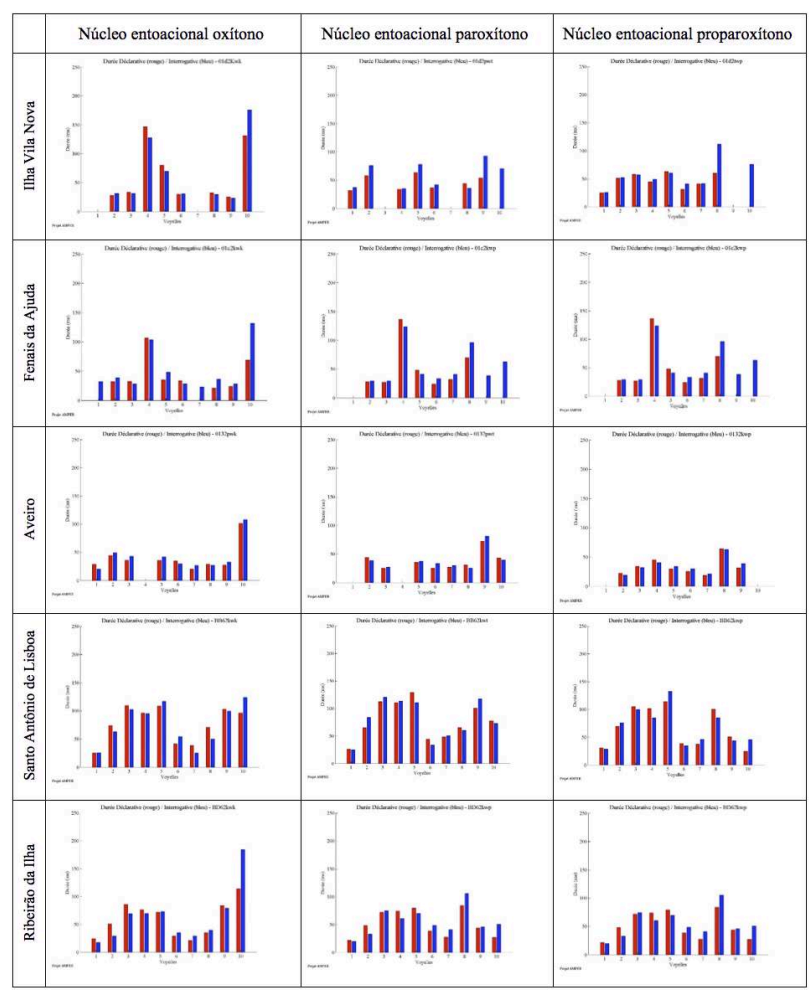

36 Com base nessa observação, foi possível verificar um comportamento distinto entre as comunidades portuguesas (Vila Nova e Fenais da Ajuda nos Açores e Aveiro na parte 
continental de Portugal) e as brasileiras (Santo Antônio de Lisboa e Ribeirão da Ilha na parte insular da capital do estado de Santa Catarina no Brasil). Para melhor observação desse comportamento, organizámos os dados de duração em bloxplots que permitem a visualização da distribuição dos dados em uma amostra, ou seja, permitem o exame da distribuição e a dispersão dos dados (Oushiro, 2017). Observe as figs. 7 e 8.

Figura 7. - Distribuição dos valores médios de duração $(\mathrm{ms})$ das vogais de frases declarativas nas amostras pesquisadas.

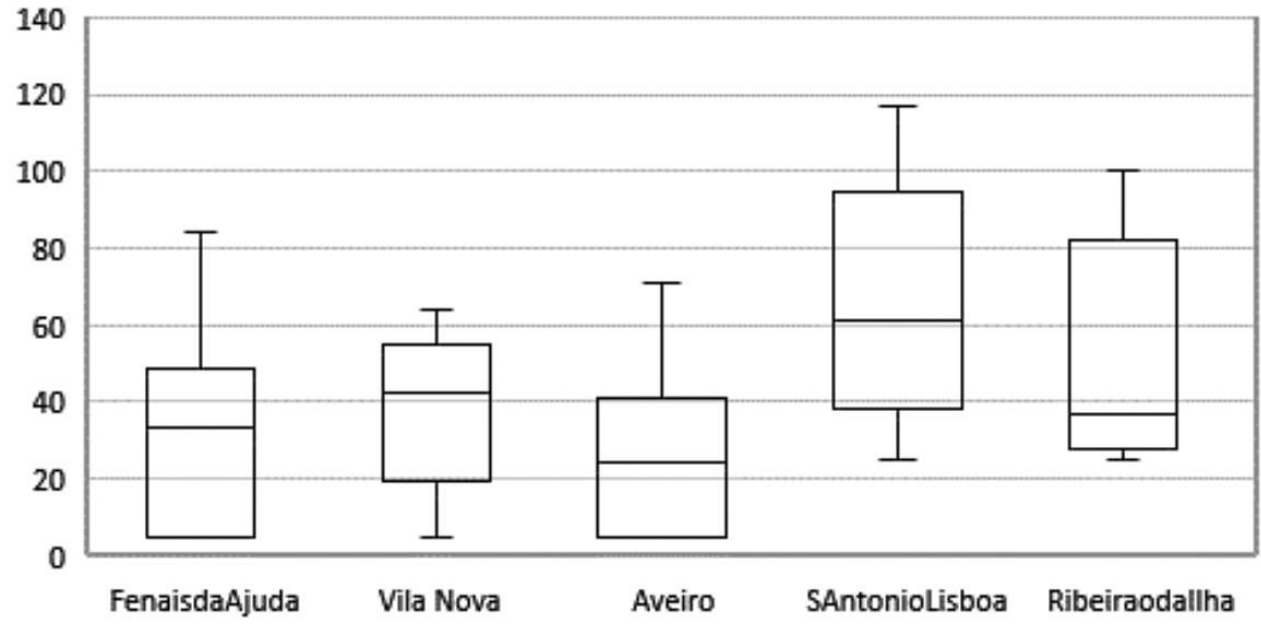

Figura 8. - Distribuição dos valores médios de duração ( $\mathrm{ms}$ ) das vogais de frases interrogativas nas amostras pesquisadas.

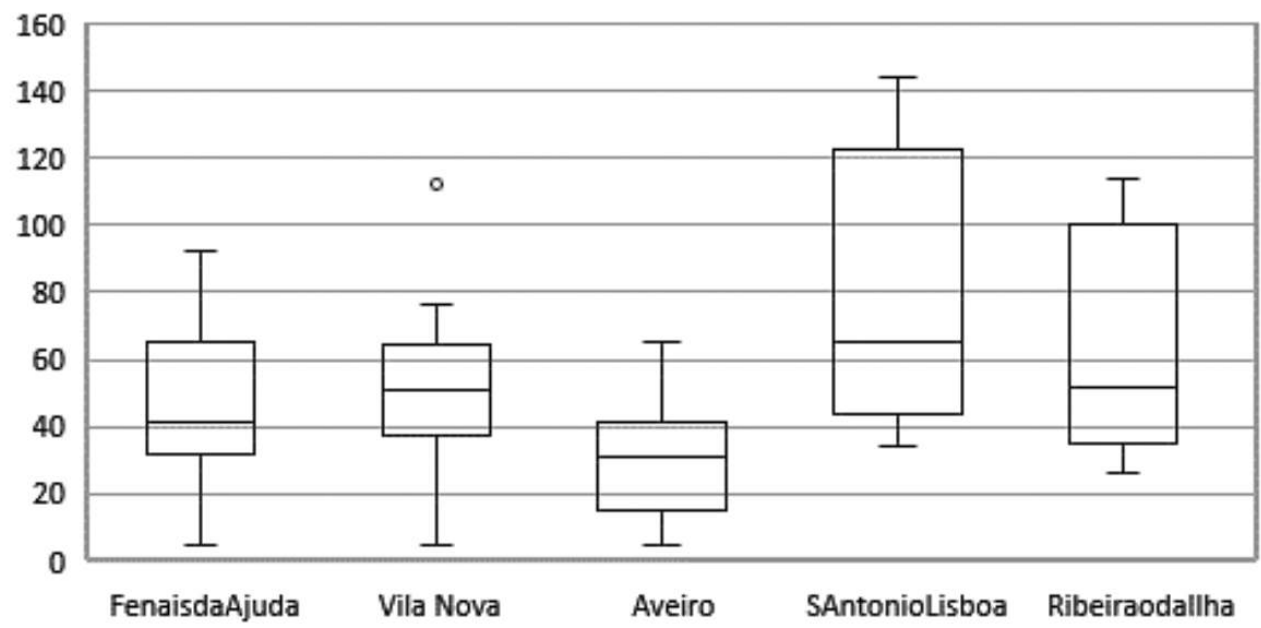

37 A linha escura interna dos bloxplots representa a mediana ${ }^{2}$ e, quanto menos dispersos estiverem os dados, maior será sua concentração em torno da mediana. A linha superior de cada bloco indica que $75 \%$ dos dados encontram-se até aquele ponto. Essa análise exploratória dos valores de duração vocálica também auxilia na confirmação de comportamentos distintos entre as comunidades portuguesas $\mathrm{e}$ as brasileiras. Se observarmos a disposição dos dados até os $50 \%$, indicada pela mediana, verificamos que os dados referentes à Ribeirão da Ilha se mostram mais coerentes com os dados das comunidades portuguesas. No entanto, a amostra referente à Santo Antônio de Lisboa 
apresenta uma maior dispersão e a distribuição dos seus dados também é distinta das demais distribuições.

Com as amostras, verificamos a normalidade dos dados através do teste de Shafiro e constatamos que, à exceção dos dados de Ribeirão da Ilha, os demais têm uma distribuição normal. A partir dessa constatação, fizemos testes de correlação entre as amostras das comunidades aqui estudadas. Isso quer dizer que, se houver correlação, as duas variáveis apresentam semelhanças na sua distribuição (Figueiredo Filho \& Silva Junior, 2009). Percebemos, então, que esses resultados também comprovam as diferenças e similitudes observadas na análise exploratória dos dados. Observe a figura 9.

Figura 9. - Gráfico de correlação forte $(r=0,81)$ e positiva entre os valores de duração das amostras de frases declarativas das comunidades de Fenais da Ajuda e Vila Nova.

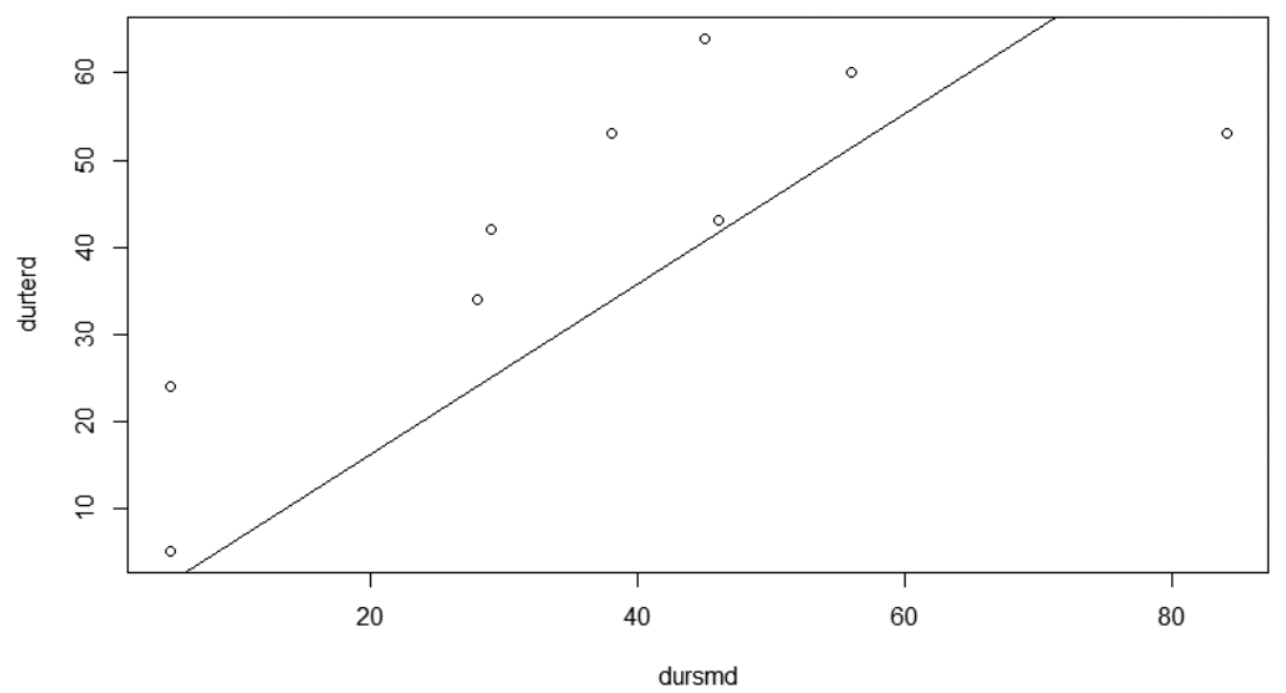

Na figura 9, são exibidos os dados de duração de frases declarativas provenientes das ilhas de São Miguel (Fenais da Ajuda) e Terceira (Vila Nova). Ainda com vista a uma análise exploratória, os dados da figura 9 mostram-se fortemente correlacionados com uma correlação de Pearson de $r=0,81^{3}$. Isso significa que os valores de duração caminham em um mesmo sentido (Barbetta et al., 2004). Essa correlação positiva também é observada entre os dados de Fenais da Ajuda e Aveiro $(r=0,82)$, Vila Nova e Aveiro $(r=0,77)$, Santo Antônio de Lisboa e Ribeirão da Ilha $(r=0,72)$, passando à moderada entre Fenais da Ajuda e Ribeirão da Ilha $(r=0,64)$, Vila Nova e Ribeirão da Ilha $(r=0,61)$, Aveiro e Ribeirão da Ilha $(r=0,56)^{4}$, Fenais da Ajuda e Santo Antônio de Lisboa $(r=0,51)$. Mostrou correlação fraca entre Aveiro e Santo Antônio de Lisboa $(r$ $=0,28)$ e Vila Nova e Santo Antônio de Lisboa $(r=0,23)$.

Agora passemos à análise dos dados das frases interrogativas. Observe a figura 10. 
Figura 10. - Gráfico de correlação forte $(r=0,76)$ e positiva entre os valores de duração das amostras de frases interrogativas das comunidades de Fenais da Ajuda e Vila Nova.

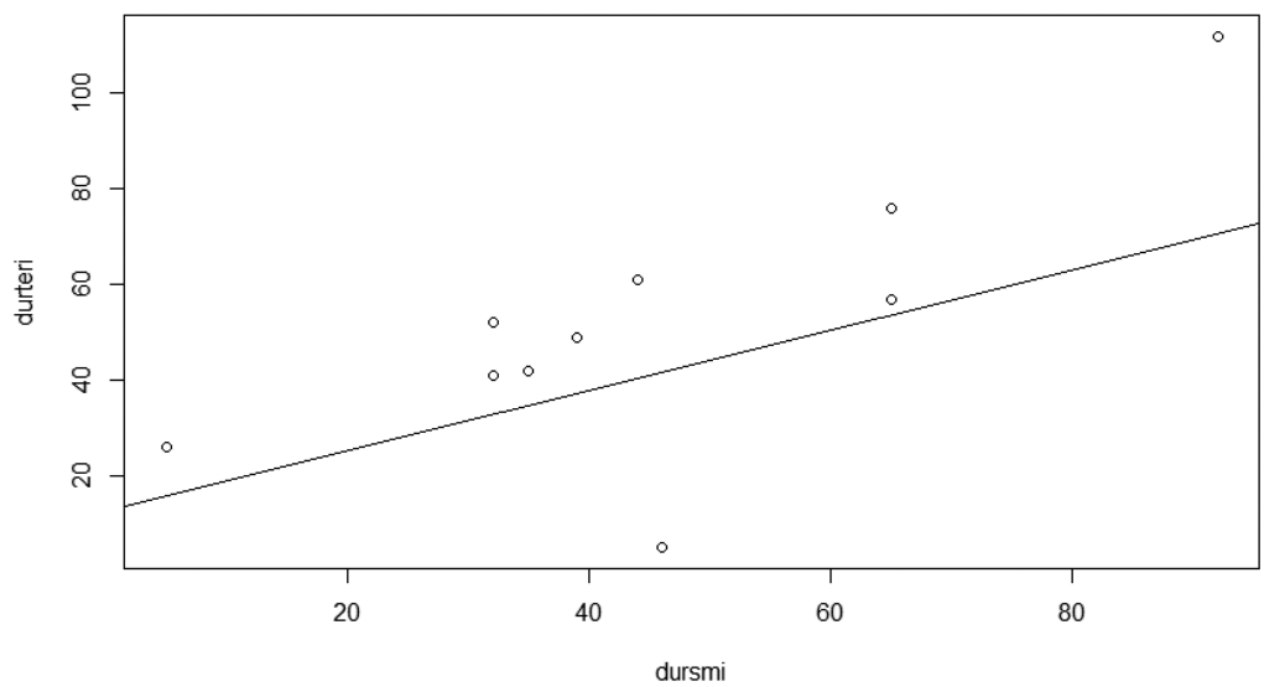

$41 \mathrm{Na}$ figura 10, são plotados os dados duração de vogais em frases interrogativas produzidas pelos sujeitos provenientes das localidades de Fenais da Ajuda da ilha de São Miguel e Vila Nova da ilha Terceira, nos Açores. Essa figura, evidencia uma correlação de Pearson forte $(r=0,76)$ e positiva. Foi verificada também correlação forte e positiva entre Fenais da Ajuda e Ribeirão da Ilha $(r=0,83)$, Vila Nova e Ribeirão da Ilha $(r=0,82)$, Santo Antônio de Lisboa e Ribeirão da Ilha $(r=0,75)$, passando a moderada entre Aveiro e Fenais da Ajuda $(r=0,66)$ e entre Aveiro e Ribeirão da Ilha $(r=0,50)$. Foi observada correlação fraca e positiva entre Santo Antônio de Lisboa e Aveiro $(r=0,39)$ e entre Santo Antônio de Lisboa e Fenais da Ajuda $(r=0,34)$. Foi verificada correlação fraca e negativa entre Santo Antônio de Lisboa e Vila Nova $(r=-0,03)$.

Com relação à duração, podemos concluir que os dados mostram que Santo Antônio de Lisboa se distancia das comunidades portuguesas, apresentando, para a maior parte dos dados, uma correlação fraca com estas comunidades. Mostra, no entanto, uma correlação forte em relação a Ribeirão da Ilha, o que seria, de certo modo esperado. Já Ribeirão da Ilha que, pelas análises iniciais, parecia apresentar características que se aproximavam das características duracionais das comunidades portuguesas, mostrou, para as frases declarativas e interrogativas, correlação positiva de forte a moderada. Esse resultado parece-nos permitir dizer que se percebe a presença dos Açores, pela semelhança, principalmente, com Fenais da Ajuda (ilha de São Miguel), nesta comunidade brasileira, também a partir de dados de duração vocálica.

\section{As respostas às nossas questões de pesquisa}

Retomamos as questões de pesquisa, para, a partir dos resultados descritos anteriormente, tentarmos dar uma resposta. Vejamos:

1. Serão verificadas, nas características prosódico-entoacionais de frases declarativas e interrogativas produzidas por falantes de duas comunidades do interior da ilha de Santa Catarina, marcas dialectais que remetam para características prosódico-entoacionais de falantes das ilhas dos Açores? 
As análises apresentadas parecem indicar que há semelhanças de comportamento entre os dados das comunidades brasileiras que tiveram colonização açoriana e algumas das localidades das ilhas dos Açores aqui estudadas, não raras vezes, mais próximas das comunidades brasileiras do que da comunidade portuguesa continental.

2. Verificadas semelhanças, elas estarão relacionadas com os movimentos da curva de $F_{0}$, localização e alinhamento do pico de $F_{0}$ nas sílabas? Ou estarão associadas com as variações de valores de $F_{0}$ e de duração apresentadas para as frases declarativas neutras e interrogativas totais?

Da observação visual dos movimentos do contorno melódico (curva de $F_{0}$ ) das frases declarativas neutras e interrogativas totais, conclui-se que há semelhanças entre as produções dos açorianos e dos florianopolitanos. Nesses casos, essas produções apresentam $F_{0}$ mais alto nas interrogativas, porém, enquanto que a curva de $F_{0}$ das interrogativas para os açorianos se apresenta mais alta do que nas declarativas em toda a sua extensão, a curva de $F_{0}$ das interrogativas dos florianopolitanos vai exibir um comportamento inverso na região nuclear, na qual passa a apresentar valores de $F_{0}$ das interrogativas bem mais baixos do que o das declarativas. As curvas de $F_{0}$ produzidas por continentais destoa com referência ao contorno melódico das produções açorianas, tanto na região pré-nuclear, como na nuclear, enquanto que, em alguns casos, o contorno melódico dos açorianos se aproxima mais dos florianopolitanos.

Quanto à localização do pico de $F_{0}$ e seu alinhamento na sílaba, o comportamento das produções nas duas comunidades brasileiras parece semelhante ao apresentado nas produções de Aveiro: o pico de $F_{0}$ nas interrogativas ocorre à direita nas tónicas. Já para as frases declarativas, há um comportamento semelhante para todas as comunidades investigadas: pico de $F_{0}$ na região nuclear composta por vocábulos oxítonos e paroxítonos ocorre preferencialmente à esquerda na pré-tónica, podendo ser também medial. Para a região nuclear composta por vocábulos proparoxítonos, o pico de $F_{0}$ ocorre à esquerda na tónica. Este último comportamento é visto também em várias outras comunidades brasileiras (Nunes, 2015; Milan, 2015; Seara \& Moutinho, 2019).

Considerando-se a variação de $F_{0}$ entre declarativas e interrogativas, percebe-se que Ribeirão da Ilha e Vila Nova mostram semelhanças, com valores de $F_{0}$ bastante mais elevados, se comparados aos dados das demais comunidades, evidenciando que, muito provavelmente, essas diferenças seriam suficientes para a identificação das modalidades, quer no pré-núcleo, quer no núcleo entoacional.

Com relação à duração, há semelhanças na distribuição dos valores apresentados pelas comunidades portuguesas e Ribeirão da Ilha. Santo Antônio de Lisboa, no entanto, distancia-se das localidades portuguesas.

Os resultados até aqui obtidos, embora denotem alguma fragilidade, parecem bastante promissores na identificação da presença açoriana na prosódia e entoação de falantes das localidades situadas na ilha de Santa Catarina (Florianópolis) colonizadas por açorianos, encoranjando-nos a um aprofundamento da pesquisa e a prosseguir neste sentido. Obviamente que, neste momento, necessitamos de um maior detalhe dos dados, considerando também as frases com um maior número de vogais, existentes nos corpora recolhidos. Será também interessante e proveitoso a aplicação de testes de perceção com ouvintes portugueses e brasileiros, das comuninades linguísticas investigadas e exteriores a elas, para testar se as diferenças/semelhanças aqui observadas são, de facto, percebidas como tal pelos respetivos ouvintes. 


\section{BIBLIOGRAFIA}

BARBETTA Pedro et al., 2004, Estatística para cursos de Engenharia e Informática, São Paulo, Atlas.

BERNARDES Maria Clara Rolão, 2008, «A entoação na ilha de São Miguel (Açores)», Language Design, número especial 2, pp. 47-55.

Boersma Paul \& WeEnink David, 2018, Praat, Doing Phonetics by Computer (versão 5.3.84). Disponível em linha em <www.fon.hum.uva.nl/praat/>.

BRESCANCINI Cláudia, 2015, «A palatização em coda em Florianópolis/SC: variáveis sociais», Working Papers em Linguística, vol. 16, n. ${ }^{\circ}$ 1, pp. 75-97.

CABral Oswaldo Rodrigues, 1970, História de Santa Catarina (2. ${ }^{\mathrm{a}}$ ed.), Rio de Janeiro, Laudes.

CONSONI Fernanda \& FERREIRA NETTO Waldemar, 2008, «A percepção de variação em semitons ascendentes em palavras isoladas no português brasileiro", in W. Ferreira Netto (coord.), Exprosodia: Resultados preliminares, San Paolo, Paulistana editora, 2016, pp. 19-23.

DANCEY Christine \& REIDY John, 2006, Estatística Sem Matemática para Psicologia: Usando SPSS para Windows, Porto Alegre, Artmed.

ENCARNAÇÃo Márcia Regina Teixeira da, 2008, «Um breve estudo do léxico conservador presente no falar ilhéu do distrito de Santo Antônio de Lisboa, litoral de Santa Catarina», Revista de estudos lusófonos, $n .^{\circ} 0$, itens 9 e 10 .

Figueiredo FilHo Dalson Britto \& Silva JunioR José Alexandre, 2009, «Desvendando os Mistérios do Coeficiente de Correlação de Pearson (r)», Revista Política Hoje, vol. 18, n. ${ }^{\circ}$ 1, pp. 115-146.

FURLAN Oswaldo Antônio, 1989, Influência açoriana no português do Brasil em Santa Catarina, Florianópolis, UFSC.

MARTINS Marcus Vinícius Moreira \& FeRreIRA NETTo Waldemar, 2010, «Prosódia e escalas de frequência: um estudo em torno da escala de semitons», ReVEL, vol. 8, n. ${ }^{\circ} 15$.

MilAN Pollianna \& KLUGE Denise Cristina, 2017, «Diferenças na região pré-nuclear entre sentenças assertivas e interrogativas do dialeto curitibano: produção e percepção», Cadernos de Estudos Linguísticos, vol. 59, n. ${ }^{\circ}$ 2, pp. 289-316.

MILAN Pollianna, 2015, Subsídios para uma análise prosódica do dialeto de Curitiba: uma contribuição ao projeto AMPER-POR, Dissertação (Mestrado em Linguística), Universidade Federal do Paraná, Curitiba.

MoutinHo Lurdes de Castro \& CoIMBRA Rosa Lídia, 2010, «Variação entoacional no português europeu no âmbito do Projeto AMPER-POR», Revista Intercâmbio, n. ${ }^{\circ}$ 22, pp. 95-105.

Moutinho Lurdes de Castro, CoIMBRA Rosa Lídia \& BERNARDES Maria Clara Rolão, 2015, «Sul de Portugal continental e Açores: Distância geográfica também distância prosódica?», in L. de Castro Moutinho, R. L. Coimbra e E. Fernández Rei (coord.), Estudos em variação geoprosódica, Aveiro, UA Editora, pp. 111-119.

Moutinho Lurdes de Castro, CoImbra Rosa Lídia, RilliaRd Albert \& Romano Antonio, 2011, «Mesure de la variation prosodique diatopique en portugais européen», Estudios de Fonética Experimental, n. ${ }^{\circ} \mathrm{XX}, \mathrm{pp} .33-55$. 
NUNES Vanessa Gonzaga, 2015, A prosódia de sentenças interrogativas totais nos falares catarinenses e sergipanos, Tese (Doutorado em Programa de Pós-Graduação em Linguística da UFSC), Universidade Federal de Santa Catarina.

NUNES Vanessa Gonzaga, RILLIARD Albert \& SEARA Izabel Christine, 2015, «Pistas prosódicas do falar catarinense: um estudo sobre interrogativas totais neutras», Revista Linguagem \& Ensino, $\mathrm{n} .{ }^{\circ} 18$, pp. 251-274.

NUNES Vanessa Gonzaga \& SEARA Izabel Christine, 2019, «A investigação da prosódia de sentenças interrogativas totais em variedades dialetais catarinenses e sergipanas com foco em diferentes metodologias», Revista Intercâmbio, n. ${ }^{\circ}$ 39, pp. 202-223.

OUSHIRO Livia, 2017, Introdução à Estatística para Linguistas (v. 1.0.1, Dez. 2017). Disponível em linha em <https://doi.org/10.5281/zenodo.822069>, Licença Creative Commons 4.0 Atribuição-Não comercial [acesso em 6 Junho 2019].

PIAZZA Walter F., 1983, Santa Catarina: sua história, Florianópolis, UFSC, Lunardelli.

SEARA Izabel Christine, 2019, «Algumas observações sobre características segmentais da variedade dialetal florianopolitana», in L. de Castro Moutinho, R. L. Coimbra e E. Fernández Rei (coord.), Estudos em variação linguística nas línguas românicas, Aveiro, UA Editora, pp. 49-68.

SEARA Izabel Christine \& MoutinHo Lurdes de Castro, (a ser publicado), A variação na entoação de declarativas neutras e interrogativas totais nas três capitais do Sul do Brasil.

SEARA Izabel Christine \& SOSA Juan Manuel, 2017, «A identidade dialetal do manezinho com foco em características entonacionais», Letras de Hoje, n. ${ }^{\circ}$ 52, pp. 51-57.

SEARA Izabel Christine, SoSA Juan Manuel \& OliveIRA Roberta Pires de, 2018, «A vitalidade identitária de contornos entonacionais característicos do falar manezinho», Gragoatá (UFF), n. ${ }^{\circ}$ 23, pp. 632-653.

SiLVA Ana Kelly Borba da, 2008, «Os Róticos na Ilha de Santa Catarina», in Anais do Centro de Estudos Linguísticos do Sul (CELSUL), pp. 1-25.

'T HART Johan, 1981, «Differential Sensitivity to Pitch Distance, Particularly in Speech», Journal of Acoustical Society of America, n. ${ }^{\circ}$ 69, pp. 811-821.

Uliano Cristiane Gonçalves, NunEs Vanessa Gonzaga \& SEARA Izabel Christine, 2015, «Pistas prosódicas no detalhe fonético: movimento intrassilábico e intersilábico da variedade chapecoense», in L. de Castro Moutinho, R. L. Coimbra e E. Fernández Rei (coord.), Estudos em variação geoprosódica, Aveiro, UA Editora, pp. 19-32.

\section{NOTAS}

1. Os dados analisados no estudo de Bernardes (2008) eram referentes à ilha de São Miguel, mais especificamente a Arrifes junto a Ponta Delgada (Costa Sul) e Ribeira Grande (Costa Norte).

2. Mediana é uma medida de tendência central que tem a característica de dividir um conjunto ao meio. Isto quer dizer que a mediana separa um conjunto em duas partes de forma que $50 \%$ dos valores sejam menores do que a mediana e os outros $50 \%$ sejam maiores do que ela (Barbetta et al ., 2004).

3. Segundo Dancey e Reidy (2006), a classificação dos valores do coeficiente de Pearson ( $r$ ) é a seguinte: $r=0,10$ até 0,30 (fraco); $r=0,40$ até 0,6 (moderado); $r=0,70$ até 1 (forte). 
4. Os dados que envolveram Ribeirão da Ilha foram calculados com o teste de correlação de Spearman para dados não normais.

\section{RESUMOS}

Esta pesquisa apresenta uma análise prosódico-entoacional de frases declarativas neutras e interrogativas totais produzidas por falantes portugueses e brasileiros, com o objetivo de averiguar da presença de traços comuns nessas duas variedades. Para o português europeu, além de Aveiro, cidade de Portugal continental, incluímos duas localidades açorianas. Para o português brasileiro, consideramos duas comunidades colonizadas por açorianos em Florianópolis. Para este estudo, privilegiamos os parâmetros: contornos da curva de $F_{0}$, posição e alinhamento do pico de $F_{0}$ na sílaba, variação de $F_{0}$ entre as modalidades e duração. Os resultados evidenciaram semelhanças entre as produções dos falantes açorianos e brasileiros, quer nos contornos da curva de $F_{0}$, quer relativamente à localização e alinhamento do pico de $F_{0}$. Também a duração mostrou semelhanças referentes às produções do Ribeirão da Ilha e as comunidades portuguesas.

Cette recherche présente une analyse prosodique de l'intonation de phrases déclaratives neutres et de phrases interrogatives totales produites par les locuteurs portugais et brésiliens, dans le but de vérifier la présence de traits communs dans ces deux variétés. En ce qui concerne le portugais européen, outre Aveiro, une ville du Portugal continental, nous incluons deux localités açoriennes. Pour le portugais brésilien, nous considérons deux communautés colonisées par des Açoriens à Florianópolis. Pour cette étude, nous privilégions les paramètres suivants : contours de la courbe $F_{0}$, position et alignement du pic $F_{0}$ dans la syllabe, variation de $F_{0}$ entre les modalités et la durée. Les résultats ont montré des similitudes entre les productions des locuteurs açoriens et brésiliens, aussi bien dans les contours de la courbe de $F_{0}$, que dans l'emplacement et l'alignement du pic de $F_{0}$. La durée a également montré des similitudes entre les productions de Ribeirão da Ilha et celles des communautés portugaises.

This research presents a prosodic-intonational analysis of neutral declarative sentences and total interrogative sentences produced by Portuguese and Brazilian speakers, with the objective of determining the presence of possible common traits between these two varieties. For European Portuguese, in addition to Aveiro, a town in mainland Portugal, we included two Azorean localities. For Brazilian Portuguese, we considered two communities colonized by Azoreans in Florianópolis. For this study, we considered the following parameters: $F_{0}$ curve contours, $F_{0}$ peak position and alignment in the syllable, $F_{0}$ variation between modalities, and duration. The results showed similarities between the productions of the Azorean and Brazilian speakers, both in the contours of the $F_{0}$ curve and in the location and alignment of the $F_{0}$ peaks. Duration also showed similarities between the productions of Ribeirão da Ilha and the Portuguese communities. 
ÍNDICE

Mots-clés: prosodie et intonation, durée, fréquence fondamentale, présence açorienne,

Florianopolis non urbain

Palavras-chave: prosódia e entoação, duração, frequência fundamental, presença açoriana, Florianópolis não-urbano

Keywords: prosody and intonation, duration, fundamental frequency, Azorean presence

\section{AUTORES}

\section{LURDES DE CASTRO MOUTINHO}

UA/CLLC-Portugal

lmoutinho@ua.pt

\section{IZABEL CHRISTINE SEARA}

UFSC/CNPq-Brasil

izabel.seara@gmail.com 